\title{
Design and Implementation of National Traditional Sports events Management Information System
}

\author{
Zhengxia Qiao \\ Zhongzhou University College of Physical Education, Zhengzhou 450044,China \\ paperiset@163.com
}

Keywords: National traditional sports, Information, Inheritance, Development.

\begin{abstract}
Chinese traditional sports culture as an important part of the world sports culture has its own unique value and significance. But with the development of the global information technology, Chinese traditional culture has been invaded step by step by modern western sports culture. Under the global information technology, we should have new innovation and strategy which can help Chinese traditional sports culture get inheritance and development constantly.
\end{abstract}

\section{Introduction}

National traditional sports culture matter to maintain and develop our outstanding culture, not only it related to the prosperity of national traditional sports culture, but also a matter of improving the strength of our culture [1]. Therefore, under the global information, heritage traditional sports culture is very important and necessary.

Modern sport is a sign of a civilized society, social modernization process also contributed to the modern sports. Since the reform and opening up, new scientific theories emerging technologies and innovation. Modern communications technology industry has become one of the fastest growing areas, humanity has entered the information age. These modern means of communication pathways enriched national traditional sports; traditional sports also take advantage of the development of national and get improvement and innovation [1].

\section{The inheritance of national traditional sports under the information technology}

The inheritance of Chinese traditional sports culture theory [1]. In a globalized environment, we need to inherit a reasonable basis for the original theory, globalization of vision, the Theory of Chinese traditional sports culture of a more deep-level mining and organize efforts to find Chinese national tradition theory of Physical Culture and Sports of modern Western culture, meeting point, and gradually improve with Chinese characteristics and the formation of national traditional sports culture theory..

The inheritance Chinese traditional sports culture model. In a globalized environment, we should try to break the tradition of the model, on the basis of keeping these family patterns, and actively explore other models to better promote the inheritance and development of Chinese traditional sports culture. To explore new modes of inheritance, we can learn the theory and methods of modern Western tradition sports culture, through television, newspapers and other media of Chinese traditional sports culture publicity [2].

Inheritance the cultural values of Chinese traditional sports. Chinese traditional sports culture of the Chinese nation is the most active and the most active part, has a very important role in the development of society.

In general, Chinese traditional sports culture has political value, economic value, cultural and social values.

Political value, Chinese National Traditional Sports in China from the weak development of sports as a sports power in the process played a very important role. Chinese traditional sports culture reveals the Chinese national culture, to promote China as an important driving factor in power. Meanwhile, traditional sports culture is also an important means of China's diplomacy is an important exchange of information with other countries, you can make China better understood 
States parties to strengthen China's position on the political culture in the world has a very important effect [2].

Economic value, Traditional Ethnic Sports can be combined with tourism, create huge economic benefits. However, the current economic value of Chinese traditional sports has been developed as well.

Humanistic values, Chinese traditional sports is benevolence, Germany, and other ethical standards as a precondition, emphasizing harmony, reveals in the humanistic aspects of values.

Social value, Chinese traditional sports culture has a unique social value, both to regulate people's behavior in everyday life, but also to cultivate the national spirit of the people.

However, in the wave of globalization, with the introduction of Western values of sport, the value system of Chinese traditional sports culture was severely damaged. Chinese traditional sports culture has a significant value, so the value of the inheritance and development of Chinese traditional sports culture is particularly important.

Chinese cultural value of traditional national sport should be the basis of inheriting the tradition of personal accomplishment, drawing on Western sports culture and value system to absorb the favorable factors, the formation of national traditional sports highlight cultural personality of the new cultural value system.

\section{Development and strategy of national traditional sports under the information technology}

Vigorously publicize the national traditional sports through modern communication and information technologies [3]. Modern communication with people's lives is a variety of smart phones, digital audio broadcasting. Amps and computer are in everywhere. Traditional Ethnic Sports can use these media technologies can be widely disseminated.

Schools in the teaching process itself is a total multimedia extensive use of traditional sports propaganda, stimulate student interest, after the lecture screen and spread over the Internet courseware to facilitate more people learn about the traditional national sport. Meanwhile the public schools can establish the appropriate traditional sports database links with other schools and effective sharing of resources, each school search according to their needs to the appropriate academic resources conducive to the spread of traditional national sport.

Government can also make full use of modern techniques, will have its own distinctive national traditional sports made impressive commercials, thus affecting their awareness from the concept, to stimulate the enthusiasm of people to participate in national traditional sports, but also can be documentary forms show the historical development of national traditional sports, and strengthen people's confidence in the national traditional sport.

You can also use the community a unique way to increase the national traditional sports publicity, such as the founder of the relevant magazine illustrations show the way to the national characteristics of traditional sports in order to attract a large audience into the traditional sports of hair to go. Or create related clubs, associations, through various forms of advocacy of national traditional sports.

Develop the industry of national traditional sports through modern market. With the continuous development of market economy, sport has gradually put on the cloak of business. Effective combination of sports and market economy can be used to the development of sports development in the creation of a new space. The current major events at home and abroad we can find elements of the business. Businesses took advantage of the media and sports product marketing, while also leveraging the investment in the business of sports for people to have impact. Therefore, traditional national sports can also help the market to develop. Meanwhile, with the progress of society, people's incomes and living standards have been greatly improved, the level of consumption also tended to increase. People have more free time as production efficiency. People are more willing to go out everyday lifestyle, to travel abroad, not only relaxation, but also to seek the true meaning of life. Sports tourism just becomes an inevitable choice. Entertainment and fun is in line with the national traditional sports such demand, so the modern market for traditional national sports promotion and display a lot of sense. 
So you want to build strong local sports tourism routes, in all kinds of attractions develop traditional ethnic sports, followed with local characteristics you want to fight national festival highlights sports tourism. Thus, while the majority of tourists in the tourist feel fully interactive national sports industry and the development of tourism industry in the charm of the traditional national sport generated great interest. Such as: the development of sports tourism in Western region, as the carrier is in the festival, folk culture and tourism resources as the basis for the media as an important means of promoting, supporting a range of sporting activities held to attract the majority of tourists. Wrestling with local ethnic characteristics, Waving Dance, hair Gus dance, martial arts, dragon boat competition, encouraging dance Lion Dance and other activities have been carried out in the area to tourists who bring the most fruitful visual feast, visitors through the site and feel deeply involved in appreciate the mystery of this ancient nation, but like a variety of forms.

Promote the development of national traditional sports through sports. In the new political environment, traditional sports to get a good development, or would like to learn from the experiences of Western sports. Therefore, the Western concept of competition and the pursuit of the concept of self-worth has become the pursuit of national traditional sports culture, traditional sports, and competitive sports to promote the development of national traditional sports [3].

National Traditional Ethnic Sports for such development provides a good platform for a growing number of national traditional sport tuned improvements and the development of relevant rules went into the Games or large game. Local cultural festival held in the relevant competitions, festive atmosphere conducive to active, but also conducive to the development of national heritage and traditional sports. In the city, you can community-based or different departments to compete as a unit in the entertainment people but also to promote the development of national traditional sports.

But it is not enough to enter the race, but also strengthen the organization and scientific management. Specializes in traditional national sports training are professionals as well as related referee coach.

One thing to note is that in the athletics of the concept of popular, traditional sports cannot purely be westernized; still want to keep some of this kind held cultural character.

Solve the problems through regulatory policies. Develop a relationship with both of things in their own internal development, but also inseparable from the influence of external factors [4]. Traditional Ethnic Sports wants to go long-term, self-development alone is not enough, have to rely on national policy regulation. If you just adapt national policy control features traditional national sport, will develop a higher level of national traditional sports.

Education policy can be a good show current national sports center, by specifying the relevant policy development projects or participating in traditional sports, for the role of traditional ethnic sports heritage is immeasurable. If you can add more than traditional sports in the regular game, so conducive to its flourishing. Competition is not only the significance of both the winning and losing the game; the game is more competition in the process of training or experience to cultural significance. Traditional Ethnic Sports has a certain ornamental, so that not only the athletes, including the audience will enjoy the whole process, feel the charm of traditional culture. Second, is to set the PE exam project. Traditional Sports included in the assessment of sport, it can cause great attention of students, enhance students' enthusiasm for learning traditional sports. Education authorities to achieve these, the development of national traditional sports have a great catalyst.

Education sector is actively implementing various policies and measures needed to maintain a sound legal system. Therefore, strengthening government legislation, try to improve the various systems, but also the traditional national sport of state regulation of large powerful countermeasures, give full play to all aspects of supervision and management capabilities to ensure the effective implementation of the traditional sports.

\section{Conclusion}

Transition from single to multiple. Accelerate the process of modernization, more and more people began to focus national traditional sports. The current exhibition of traditional national sports school is mostly single, mostly traditional martial arts based. This is no longer adapted to the 
needs of society, and therefore different styles of traditional sports into the school are the trend of its development.

Merge with western Sports. Western sports culture has been dominated in school sports, the culture development of national traditions make the two cultures collide. Now, Learning from each other is the way the two cultures. Therefore, traditional national sports should learn from the west and reserved the rich cultural heritage.

The integrated of school sports. School sports is a unified whole. When we do a questionnaire to different primary and secondary schools as well as universities carried out a detailed survey found that the introduction of different types of National Traditional Sports and integration with the West is the traditional national sport of sports development in schools current trends. From the vertical perspective, is a lifelong sports school sports the most important stage, students of sports consciousness is very important, so students at all stages should have the appropriate level of the curriculum, so students throughout the entire learning process. This is the traditional national sport in school sports in the big trends. According to different ages and stages of different activities, appropriate education, so that national traditional sports to form a coherent whole, but also to be a good inheritance. To achieve the development of national traditional sports in the modern context, not only the needs of the school spread, need the government 's macro-control, the development of relevant policies facilities, increased supervision, but also need the help of modern information resources to intensify propaganda . Finally, the development of sports and cultural industries should be conjunct with the status of market economy in order to achieve sustainable development of the national traditional sports.

\section{References}

[1] Q.J. Zhao. The Research and Development of Chinese Traditional Sports, Sports Sciences, 2011.8

[2] X.M. Hu. The Aesthetic Value of National Sports, Beijing Physical Education, 2011.34.

[3] S.Zhao and G.X. Duan. Research status and prospects of national traditional sports, Sport and Science, 2002.23

[4] B.LI. The Summary of Traditional Sports, Martial arts sport, 2010. 7 